\title{
REGIMES DE FLEXIBILIZAÇÃO E SENTIDOS DO TRABALHO PARA DOCENTES DE ENSINO SUPERIOR EM INSTITUIÇÕES PÚBLICAS E PRIVADAS
}

\author{
FLEXIBLE WORK ARRANGEMENTS AND THE MEANING OF WORK FOR TEACHERS \\ OF HIGHER EDUCATION IN PUBLIC AND PRIVATE INSTITUTIONS
}

REGIMES DE FLEXIBILIZACIÓN Y SENTIDOS DEL TRABAJO PARA DOCENTES

DE ENSEÑANZA SUPERIOR EN INSTITUCIONES PÚBLICAS Y PRIVADAS

\author{
Anelise D' Arisbo ${ }^{1}$ \\ Daiane Boff ${ }^{2}$ \\ Andrea Poleto Oltramari ${ }^{3}$ \\ Julice Salvagni ${ }^{4}$
}

Resumo Este artigo objetivou compreender o sentido do trabalho para o docente de ensino superior em instituições públicas e privadas em seus diversos regimes de flexibilização do trabalho, com base na identificação de elementos da racionalidade instrumental e subjetiva. Assim, a coleta de dados contou com fontes múltiplas, tais como a análise documental das instituições e dos contratos de trabalho dos docentes, a observação direta e as entrevistas realizadas presencialmente. Como resultado, percebeu-se que: há preponderância do sentido laboral substantivo sobre o sentido instrumental; a flexibilização altera a percepção da atuação individual e interfere no seu sentido substantivo; e a vida é arranjada a partir da organização do trabalho flexibilizado.

Palavras-chave sentido do trabalho; docência; flexibilização.

\begin{abstract}
This article aims to understand the meaning of the work for the higher education teacher in public and private institutions in their various regimes of work flexibility based on the identification of instrumental and subjective rationality elements. The collection of data had multiple sources, such as the documentary analysis of institutions and teachers' work contracts, direct observation and personal interviews. As a result it was noticed that: there is a preponderance of the substantive meaning of the work on the instrumental sense; the flexibilization alters the perception of individual performance and infers on its substantive sense, and life is arranged from the organization of work flexibilized.
\end{abstract}

Keywords sense of work; teaching; flexibility. 


\section{Introdução}

Estudos recentes apontam para a reconstrução do poder pelas organizações sobre as relações de trabalho, de forma que a regulação do trabalho está sendo transferida do social para o privado. O resultado é o aumento da informalidade dos trabalhadores, a destruição da rede de proteção social ao trabalhador e o aumento da desigualdade social (Piccinini, Rocha-de-Oliveira e Rubenich, 2006; Vasapollo, 2005). O sentido do trabalho docente pode estar associado a tais elementos apontados, uma vez que sua característica vem se alterando, resultado do crescente aumento do número de instituições de ensino superior (IES) no Brasil (INEP, 2015).

A discussão do sentido do trabalho nas organizações contemporâneas, do ponto de vista das suas influências na constituição do homem como sujeito, parece ser uma oportunidade de repensar a importância deste na constituição do papel das organizações na humanização das atividades laborais (Araújo e Sachuk, 2007). Desta forma, compreende-se este sentido como dimensão social e histórica na qual se insere. Assim, para compreendê-lo com base das suas relações, objetivou-se analisar o sentido do trabalho do docente de ensino superior em instituições públicas e privadas em seus diversos regimes de flexibilização.

Para tanto, a pesquisa de natureza qualitativa foi aplicada a docentes de ambas as redes, em distintos regimes de trabalho. Pretende-se evidenciar elementos que permitam a compreensão das condições às quais o docente de nível superior está submetido em instituições públicas e privadas, como também os aspectos intrínsecos que incidem sobre sua atuação e constituem a dimensão trabalho em suas vidas. O artigo contempla a revisão da literatura relacionada, os procedimentos metodológicos, a apresentação e análise dos resultados, seguidos das considerações finais.

\section{Sentidos do trabalho}

Trata-se de um construto psicológico multidimensional e dinâmico, e que resulta da interação entre variáveis pessoais e ambientais relacionadas ao trabalho. Na visão sociológica do pensamento weberiano, tem-se como princípio que os sentidos atribuídos ao trabalho podem estar relacionados aos tipos de racionalidades presentes na sociedade e nas organizações (Andrade, Tolfo e Dellagnelo, 2012; Tolfo e Piccinini, 2007).

Andrade, Tolfo e Dellagnelo (2012) partem do pressuposto de que os sentidos atribuídos ao trabalho estão relacionados a duas racionalidades presentes na sociedade e nas organizações: a instrumental e a substantiva. Os autores tomam como base a pesquisa de Serva (1997), que elencou como elementos 
constitutivos da ação racional instrumental a projeção utilitária das ações das pessoas, objetiva os fins, o aumento de poder, a maximização dos recursos, o êxito, o desempenho, a utilidade, a rentabilidade e a estratégia interpessoal (influência planejada sobre outrem); já como elementos da ação racional substantiva estão a busca pela autorrealização, o entendimento (ações pelas quais se estabelecem acordos e consensos racionais), o julgamento ético, a autenticidade (integridade, honestidade e franqueza dos indivíduos nas interações), os valores emancipatórios (direcionados para o bem-estar coletivo) e a autonomia. A diferença entre os sentidos do trabalho segundo a visão das racionalidades instrumental e subjetiva fica evidenciada no Quadro 1.

Quadro 1
\begin{tabular}{|ll|}
\hline Tipos de sentidos do trabalho sob a perspectiva da racionalidade \\
\hline Sentido instrumental do trabalho & Sentido substantivo do trabalho \\
\hline - Garante a sobrevivência & - Possibilita autonomia \\
- Permite retorno financeiro & - Permite desenvolvimento de relacionamentos \\
- Possibilita segurança financeira & satisfatórios \\
- Possibilita independência financeira & - Possibilita satisfação pessoal \\
- É útil para a empresa & - Possibilita autorrealização \\
- Possibilita reconhecimento material & - Possibilita aprendizagem e desenvolvimento \\
e financeiro & - Possibilita sentimento de vinculação \\
\end{tabular}

Fonte: Andrade, Tolfo e Dellagnelo, 2012.

Discussões adicionais na vertente sociológica que podem ser aqui relacionadas apresentam-se acerca da apreensão das relações da classe-que-vivedo-trabalho (Antunes, 2003; 2005; 2014) e da classe de batalhadores (Souza, 2010). O sentido do trabalho, portanto, precisa ser associado à classe social (não definida apenas pela dimensão econômica, mas por um modo de viver, por símbolos e sistemas). Ou seja, compreender o sentido é compreender todo o contexto histórico e social no qual o trabalho e o trabalhador se inserem. Essa compreensão abarca os temas da divisão sexual do trabalho, do terceiro setor, das modificações no processo produtivo, da vigência da sociedade do desemprego estrutural, da formação e da luta de classes (Souza-Lobo, 2011; Harvey, 2001; Cattani, 1996, Mészáros, 2009).

Nesse último aspecto, as modificações das relações de trabalho necessitam abranger a consciência coletiva, a qual vai muito além do sentido individual do trabalho: 
A (re)produção social, mesmo de uma consciência encapsulada na forma do 'eu', não tem outra maneira de se processar senão coletivamente. A consciência é relacional e por isso mesmo que está plenamente permeada pelas contradições e antagonismos típicos das relações sociais sob o sociometabolismo do capital (Ferraz, 2015, p. 128).

Entretanto, ainda que atingida a formação de uma consciência de classe, a dificuldade de romper com a lógica vigente do movimento de (re)produção do capital permanece, pois a consciência de classe acaba por ser engendrada pela práxis coletiva no trabalho (Ferraz, 2015).

Importa adicionar que, na área de administração, Morin (2001) tem sido o alicerce para a maioria dos estudos nacionais e internacionais sobre o sentido do trabalho em uma base funcionalista. Outrossim, a presente pesquisa opta por aceitar a recomendação de Silva e Simões (2015) de que novas pesquisas sobre o assunto sejam baseadas em outros modelos e linhas teóricas.

Assim, no âmbito das relações de trabalho, torna-se pertinente a discussão acerca do sentido do trabalho de forma a expandir o entendimento das suas dimensões. Isso, pois, desvelar o sentido do trabalho é fundamental para compreender a dimensão social e histórica na qual o trabalho se insere, na forma como é capturado e sentido pelo trabalhador e pela análise que se estabelece por uma racionalidade instrumental e subjetiva, individual e coletiva.

\section{Flexibilização do trabalho}

Se dentro das organizações ocorreram mudanças nos modelos de produção, o mesmo ocorreu com o trabalho estendido para âmbitos alheios ao organizacional, mas ainda dependentes deste. A regulação das relações de trabalho está sendo transferida do social para o privado. O resultado é o aumento da informalidade, a destruição da rede de proteção social ao trabalhador e o aumento da desigualdade social (Piccinini, Rocha-de-Oliveira e Rubenich, 2006; Vasapollo, 2005).

Chahad (2003) organizou uma tipologia dos novos padrões de trabalho, com ênfase no volume de emprego e na duração da jornada laboral. Como principais modalidades de vínculos, cita o trabalho temporário, o em tempo parcial, o job sharing (dois ou mais trabalhadores responsáveis por uma mesma tarefa), a terceirização e a suspensão temporária de contrato. Já quanto ao tempo de trabalho, destaca as horas extras, o banco de horas, a jornada laboral flexível, turnos e a semana reduzida. Fica caracterizada, assim, a flexibilização do trabalho, que pode ser vista como forma de superar as situações de rigidez e de aumentar a competitividade das organizações, ao 
permitir a redução do emprego e a facilidade no ajuste do custo e do nível de produção pela mobilidade dos recursos humanos (Piccinini, Rocha-deOliveira e Rubenich, 2006). Dessa forma, esta flexibilização tende à precarização das condições laborais.

Dentre as modalidades de flexibilização, as formas externas de trabalho geralmente desobrigam as organizações das funções de supervisão e controle e fazem com que os sujeitos se tornem patrões de si mesmo. Com isso, este é forçado a se desdobrar em sua atividade para cumprir as exigências de produtividade e qualidade exigidas. Os trabalhadores externos "estão cada vez mais escravos do capitalismo e trabalham sem que façam perceber, sob condições mais precárias, que remetem às formas de trabalho anteriores à grande indústria" (Colli, 2000, p. 17).

Essas mudanças no mundo do trabalho modificam também o perfil do trabalhador (Lancman e Sznelwar, 2004). Ademais, as transformações percebidas ou não nas relações de trabalho e no cenário do mundo laboral influenciam o estado emocional dos homens e mulheres. A violência e o assédio moral, presentes no cotidiano das organizações, contribuem para intensificar a precarização, e o individualismo inerente a estes espaços é um importante impulsionador deste fenômeno (Linhares e Siqueira, 2014).

Todos esses fatores levam à compreensão de que não apenas as relações laborais incidem na apreensão do sentido do trabalho, como incluem fatores instrumentais e que influenciarão as percepções individuais. A própria flexibilização, enquanto relacionada ao tipo de contrato e retorno financeiro auferido, pode ser tida como elemento instrumental, mas nem por isso deixa de produzir efeitos subjetivos.

\section{Trabalhador docente}

Ao observar a trajetória histórica da constituição do trabalho docente no Brasil, compreende-se a massificação do ensino como consequência da chamada democratização do ensino superior: entre 2003 e 2014, houve aumento de $96,5 \%$ na matrícula nesse nível. Diferenças entre a rede pública e privada de ensino são sensíveis: $82,9 \%$ dos docentes da rede pública têm doutorado e atuam em regime de trabalho de tempo integral, enquanto 11,4\% atuam em tempo parcial e 5,7\% são horistas (ver Gráfico 1). Já na rede privada, conforme se observa no Gráfico 2, o mestrado é o grau de formação mais frequente e o regime de trabalho prioritário é o parcial, com $40,4 \%$ dos docentes, frente a $24,4 \%$ em tempo integral e $35,2 \%$ de horistas. Em 2014 havia 383.386 funções docentes em exercício na educação superior no Brasil, dos quais 57,5\% tinham vínculo com IES privada e $42,5 \%$ com IES pública (INEP, 2015). 
Gráfico 1

Número de funções docentes na educação superior, por categoria administrativa, segundo o regime de trabalho na Rede Pública.

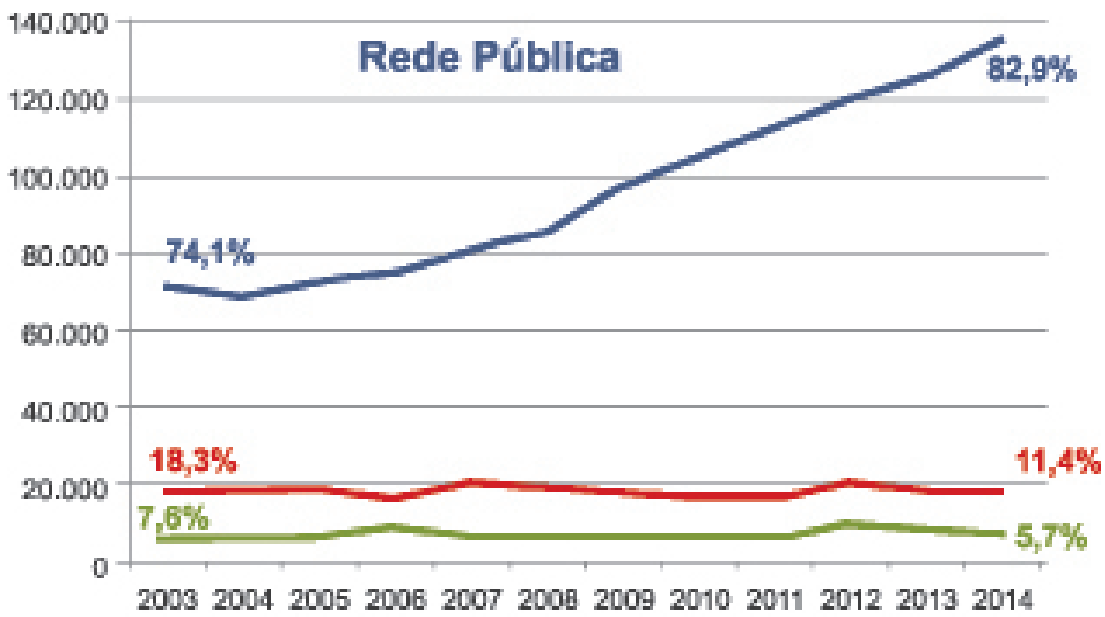

- Tempo Integral - Tempo Parcial - Horista

Gráfico 2

Número de funções docentes na educação superior, por categoria administrativa, segundo o regime de trabalho na Rede Privada

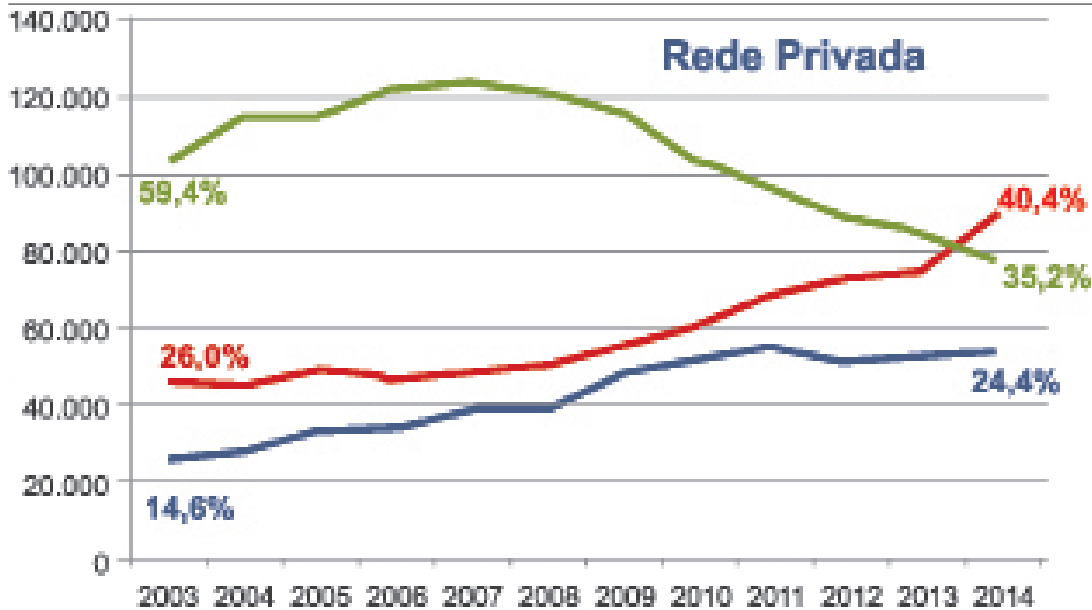

200320042005200620072008200920102011201220132014

Tempo Integral Tempo Parcial - Horista

Fonte: INEP (2015). 
Outro ponto que evidencia diferenças no trabalho docente é a distribuição de regimes de trabalho por tipo de IES, como ilustra o Gráfico 3.

\section{Gráfico 3}

Participação percentual de funções docentes na educação superior, por regime de trabalho, segundo a organização acadêmica

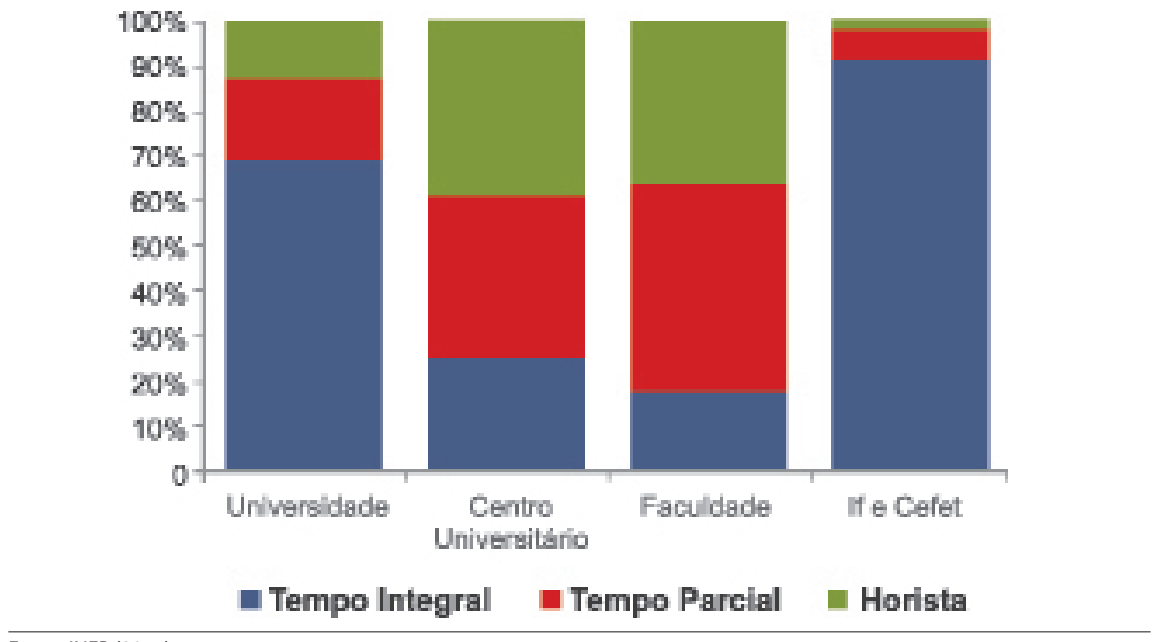

Fonte: INEP (2015).

Nota: If - Instituto federal; Cefet - Centro Federal de Educação Tecnológica Celso Suckow da Fonseca.

Tais características diferenciam as relações e o sentido atribuído ao trabalho por docentes. Outras preocupações concernem à intensidade do produtivismo acadêmico (Nascimento, 2010; Alcadipani, 2011; Misoczky e Goulart, 2011; Spink e Alves, 2011). São vários os meios utilizados para a cobrança por produção científica. Nesse ponto, Alcadipani (2011) aponta para uma lógica corporativa e gerencialista nas organizações de ensino, através da tabela de pontuação da Coordenação de Aperfeiçoamento de Pessoal de Nível Superior (Capes) e outros mecanismos de ranqueamento e quantificação. Com a quantidade sobrepondo-se à qualidade, segundo o autor, o resultado são cursos enlatados, esvaziamento da reflexão, ataques à liberdade acadêmica, transformação do aluno em cliente, enfim, a 'McDonaldização' do ensino, considerada pelos autores um ataque ao acadêmico de vocação.

Esse fator é preocupante, pois revela a função das instituições de ensino, em especial a universidade. De acordo com Misoczky e Goulart (2011), a universidade está na totalidade social e, ao mesmo tempo em que se constitui em expressão da sociedade e das forças e ideias hegemônicas, tem a responsabilidade de refletir, criticar e antecipar-se na construção de alternativas. Entretanto, a invasão do gerencialismo com ênfase na eficiência, definida como produtivismo no trabalho universitário, é visível em todas as instâncias. Para Paula (2009), isso seria resultado da influência americana no sistema de ensino no Brasil, com base na Reforma 
Universitária (lei n. 5.540/68), que redundou em uma linguagem tecnicista e empresarial de eficiência, eficácia e produtividade no ensino superior. Dessa forma, a instituição universitária passou a associar os aspectos ideais (ensino e pesquisa) aos funcionais (serviços), o que possibilita a expansão da educação superior e da sociedade de consumo. Ou seja, também nesse âmbito é identificado o processo de 'McDonaldização' do ensino, que passa a consolidar a mercantilização do ensino superior no Brasil. Frente a isso, Misoczky e Goulart (2011) sugerem o abandono da passividade em relação ao constituir social das normas vigentes no meio, bem como em relação à estrutura de produção e de avaliação dos acadêmicos.

As medidas assumidas, na década de 1960, pela Reforma Universitária e pelo Conselho Federal de Educação possibilitaram a ampliação do ensino superior privado por meio de estabelecimentos isolados, o que fortaleceu a dissociabilidade entre ensino e pesquisa. Essas instituições evoluíram para a condição de grandes empresas, algumas se tornaram universidades e passaram a se constituir, a partir dos anos 1980, como empreendimentos capitalistas de poder (Cacete, 2014). Com isso, ocorre a expansão do universo social do capital, que resulta na performatividade competitiva das instituições de ensino (Ball, 2004).

Esses fatores têm sido percebidos da perspectiva da formação docente (Barretto, 2010; Cacete, 2014), que, por sua vez, também implica na qualidade da formação escolar. Contudo, a expansão do ensino tem ainda outras consequências, como as que tangem à qualidade dos processos de ensino. Se, por um lado, a formação superior deixa de ser monopólio das universidades elitistas, por outro se abrem possibilidades para o ensino de massa (Rocha-de-Oliveira, Piccinini, 2012), que torna menos rígidos e mais questionáveis os modelos de educação. Com isso, o valor do ensino diminui - tanto o valor do certificado, quanto o do salário do docente.

Dessa forma, como resultado da massificação do ensino, o trabalho docente por vezes adota o regime de flexibilização, especialmente no nível superior, o que naturaliza elementos caracterizados por Chahad (2003) na sua aqui já mencionada tipologia dos novos padrões de trabalho. Na dinâmica produtiva, soma-se às jornadas de trabalho a obrigatoriedade de publicação dos docentes que atuam em nível superior. Ao pretenderem constituir uma carreira de produção acadêmica, acaba-se por naturalizar até mesmo o enfraquecimento da qualidade das pesquisas difundidas em revistas e eventos científicos. Assim, em meio a esse cenário, importa conhecer o sentido do trabalho para o docente, mapeando as disfunções da transformação profissional ao longo do tempo e suas implicações na construção das subjetividades pelo e no trabalho.

\section{Como encontrar o sentido}

Através de pesquisa qualitativa com docentes selecionados pelos critérios da acessibilidade e da tipicidade (Vergara, 2006), ou seja, em diferentes tipos de instituições e regimes de trabalho, objetivou-se identificar os traços que, 
para o público da pesquisa, caracterizam os sentidos atribuídos ao trabalho. Optou-se por entrevistar docentes das redes pública e privada nos diferentes tipos de contratos de trabalho.

Assim, a coleta de dados contou com fontes múltiplas, tais como a análise documental das instituições e dos contratos de trabalho dos docentes, a observação direta e entrevistas em profundidade (Minayo, 2011) aplicadas presencialmente. Para estas, foi elaborado roteiro com 13 perguntas abertas, com base nos elementos tidos como constitutivos do sentido do trabalho com base na literatura.

As entrevistas semiestruturadas foram aplicadas de janeiro a março de 2016 e tiveram duração média de uma hora. Com autorização dos entrevistados, as entrevistas foram gravadas e posteriormente transcritas.

Dez docentes com o perfil previamente delineado foram convidados e aceitaram participar da entrevista. Foram informados quanto aos objetivos da pesquisa e à garantia de sigilo em relação a suas identidades. As características dos participantes são apresentadas na Quadro 2, na qual se adotam nomes fictícios.

Quadro 2

\begin{tabular}{|c|c|c|c|c|c|c|c|}
\hline \multicolumn{8}{|c|}{ Perfil dos entrevistados } \\
\hline Entrevistado & Idade & Escolaridade & Instituição & Vínculo & $\begin{array}{c}\text { Tempo de } \\
\text { instituição }\end{array}$ & $\begin{array}{c}\text { Carga } \\
\text { horária } \\
\text { média }\end{array}$ & $\begin{array}{c}\text { Renda } \\
\text { familiar } \\
\text { líquida } \\
\text { aproximada }\end{array}$ \\
\hline Brenda & 31 & Mestre & Pública & $\begin{array}{c}\text { Estatutário- } \\
\text { Integral }\end{array}$ & 5 anos & 40 h DEE* & $\mathrm{R} \$ 13.000,00$ \\
\hline Amora & 42 & Mestre & Pública & $\begin{array}{c}\text { Estatutário- } \\
\text { Integral }\end{array}$ & 5 anos & 40 h DEE* & $\mathrm{R} \$ 15.000,00$ \\
\hline Maurício & 36 & Mestre & Pública & $\begin{array}{c}\text { Estatutário- } \\
\text { Integral }\end{array}$ & 3 anos & 40 h DEE* & $\mathrm{R} \$ 14.000,00$ \\
\hline José & 32 & Doutor & Pública & $\begin{array}{c}\text { Estatutário- } \\
\text { Integral }\end{array}$ & 6 anos & 40 h DEE* & $\mathrm{R} \$ 18.000,00$ \\
\hline Rafael & 33 & Mestre & Privada & $\begin{array}{c}\text { Celetista- } \\
\text { Horista }\end{array}$ & 7 anos & $6 \mathrm{~h}$ & $\mathrm{R} \$ 4.800,00$ \\
\hline Marina & 33 & Mestre & Privada & $\begin{array}{c}\text { Celetista- } \\
\text { Horista }\end{array}$ & 5 anos & $12 \mathrm{~h}$ & $\mathrm{R} \$ 8.000,00$ \\
\hline Fernando & 34 & Mestre & Privada & $\begin{array}{l}\text { Celetista- } \\
\text { Integral }\end{array}$ & 7 anos & $40 \mathrm{~h}$ & $\mathrm{R} \$ 8.000,00$ \\
\hline Daniela & 64 & Doutor & Privada & $\begin{array}{l}\text { Celetista- } \\
\text { Integral }\end{array}$ & 12 anos & $40 \mathrm{~h}$ & $\mathrm{R} \$ 6.400,00$ \\
\hline Douglas & 42 & Especialista & Privada & $\begin{array}{c}\text { Celetista- } \\
\text { Horista }\end{array}$ & 11 anos & $8 \mathrm{~h}$ & $\mathrm{R} \$ 8.000,00$ \\
\hline Ana & 36 & Mestre & Privada & $\begin{array}{c}\text { Celetista- } \\
\text { Horista }\end{array}$ & 3 anos & $12 \mathrm{~h}$ & $\mathrm{R} \$ 7.200,00$ \\
\hline
\end{tabular}

Fonte: As autoras.

Nota: DEE - Regime de Dedicação Exclusiva. 
Como dados adicionais, importa citar que os entrevistados da rede pública também ocupavam cargos como coordenador de ensino de graduação, coordenador de curso de graduação, diretor de ensino e diretor geral de campus, o que indica a demanda da rede pela participação na gestão. Ainda assim, mantinham as atividades docentes e a qualquer tempo a ocupação do cargo podia ser interrompida. Quanto à instituição privada, dois dos docentes ocupavam cargos de coordenador de curso de graduação, e um, o cargo de coordenador de curso de pós-graduação. As entrevistas foram realizadas em três cidades da mesma região no interior do Rio Grande do Sul, não diretamente indicadas no Quadro 2, com o propósito de preservar a identidade dos entrevistados.

Para a análise, foi efetuada a tabulação dos dados em tabela Excel@ única, com o objetivo de efetuar a categorização dos dados coletados a posteriori bem como a identificação das unidades de sentido para efetivação de análise de conteúdo (Bardin, 2000). Assim, as categorias encontradas foram: relevância social do trabalho; imagem da profissão; sentimento de vinculação com o trabalho; sentimento de pertença a uma classe trabalhadora; e flexibilização do trabalho e relação entre vida pessoal e profissional.

\section{Os sentidos refletidos}

Aprecia-se aqui a análise dos dados que busca responder o objetivo de pesquisa proposto. Buscou-se respeitar as especificidades entre as redes pública e particular de ensino. Não ater-se-á a questões individuais, mas às percepções resultantes da organização do trabalho, pois mesmo que todos atuem em regime de flexibilização, há diferenças sensíveis nas relações de trabalho.

\begin{tabular}{|c|c|}
\hline Categorização da anális & \\
\hline Categorização & Instituição privada \\
\hline $\begin{array}{l}\text { Relevância social do } \\
\text { trabalho }\end{array}$ & $\begin{array}{l}\text { Percebem a docência como elemento de transformação do aluno, seja de } \\
\text { forma instrumental ou como corresponsável pelo aprendizado. Buscam } \\
\text { instigar a reflexão do aluno, preocupam-se com transmissão de experiência } \\
\text { e estabelecimento de rede de relações. }\end{array}$ \\
\hline Imagem da profissão & $\begin{array}{c}\text { Divergência entre o sentido do trabalho para o docente e a imagem que a } \\
\text { sociedade possui da docência. Notam uma simplificação da atividade docente } \\
\text { por parte da sociedade ao perceber apenas a atuação dentro de sala de aula } \\
\text { como trabalho efetivo. }\end{array}$ \\
\hline
\end{tabular}

continua> 


\begin{tabular}{|c|c|c|}
\hline \multicolumn{3}{|l|}{ Categorização da análise } \\
\hline $\begin{array}{l}\text { Sentimento de } \\
\text { vinculação com o } \\
\text { trabalho }\end{array}$ & $\begin{array}{c}\text { A atuação do docente vai além } \\
\text { do âmbito do ensino, atinge } \\
\text { pesquisa, extensão e gestão. Esse } \\
\text { envolvimento resulta na progressão } \\
\text { na carreira e em um compromisso } \\
\text { que parece ser maior com a } \\
\text { instituição do que com o aluno. }\end{array}$ & $\begin{array}{l}\text { Nas instituições privadas existe um } \\
\text { compromisso maior com o aluno do } \\
\text { que com a instituição. A docência } \\
\text { nem sempre é a principal atividade } \\
\text { dos professores e é vista como a } \\
\text { segunda profissão. }\end{array}$ \\
\hline $\begin{array}{l}\text { Sentimento de } \\
\text { pertença a uma classe } \\
\text { trabalhadora }\end{array}$ & \multicolumn{2}{|c|}{$\begin{array}{l}\text { A estima pela profissão surgiu como um fator reiteradamente evidenciado, } \\
\text { ainda que a visão acerca do que é ser professor ou de sua função social não } \\
\text { seja a mesma. O que se percebeu foi uma identificação maior com a atividade } \\
\text { de docência, ou com o que se acredita sê-la, do que com a classe. }\end{array}$} \\
\hline $\begin{array}{l}\text { Flexibilização do } \\
\text { trabalho }\end{array}$ & $\begin{array}{l}\text { Os professores do ensino público } \\
\text { veem a flexibilização como fonte de } \\
\text { benefícios e adequada à natureza da } \\
\text { profissão. }\end{array}$ & $\begin{array}{l}\text { Para os docentes das instituições } \\
\text { privadas, o trabalho flexibilizado já } \\
\text { é algo naturalizado, mesmo que o } \\
\text { trabalho domiciliar docente não seja } \\
\text { entendido como trabalho aos olhos } \\
\text { da sociedade. }\end{array}$ \\
\hline $\begin{array}{l}\text { Relação entre vida } \\
\text { pessoal e vida } \\
\text { profissional }\end{array}$ & \multicolumn{2}{|c|}{$\begin{array}{l}\text { A visão que os docentes têm de si mesmos se modifica pelo trabalho, } \\
\text { o qual é percebido como indissociável da vida pessoal. }\end{array}$} \\
\hline
\end{tabular}

Fonte: As autoras.

Os dados são agrupados conforme categorização efetuada (Quadro 3) e discutidos de acordo com as especificidades entre as redes de ensino. As maiores diferenciações entre as redes foram identificadas nas categorias relacionadas ao sentimento de vinculação e à flexibilização do trabalho.

\section{Relevância social do trabalho}

Nessa categoria é percebida a função social da docência como elemento de transformação do aluno, seja de uma forma instrumental, seja como corresponsável pelo aprendizado do aluno. Com isso, observa-se o sentido substantivo do trabalho (Andrade, Tolfo e Dellagnelo, 2012), já que é percebida a crença de que sua atividade contribui para a sociedade. Assim, Brenda, uma das entrevistadas, relata a mudança que o professor gera na vida do aluno: 
Eles entram sem perspectiva nenhuma e a gente consegue introduzir toda essa parte do ensino formal de como é importante, de como pode facilitar e ajudá-los a crescer, profissionalmente, como pessoas...

Daniela acredita na educação como forma de modificar pessoal e profissionalmente as pessoas. Ratifica que a educação foi elemento transformador de sua história, uma forma de responder ao preconceito e transmite isso aos alunos.

Já Marina fala sobre a responsabilidade do aluno no aprendizado:

As pessoas têm que se empenhar mais. Não depende só do professor certas situações.

Para Brenda, está sempre presente a insatisfação por não conseguir atingir a todos os estudantes, em parte pelo desinteresse dos próprios alunos, fator destacado por Douglas, que afirma:

A gente tem turma de 50 alunos, às vezes, e sei lá, tu tens talvez $10 \%$ que são muito interessados, tem mais uns 20, 30 que são interessados o suficiente. Tu tens uma massa que é inerte, que está lá, não atrapalha. E tem os que estão sempre descontentes. Eu nem relevo [sic] muito. Mas eu só fico chateado que a grande maioria é desinteressada. Eles não entendem.

São percebidas a corresponsabilidade tanto do aluno como do professor e a dificuldade de lidar com uma maioria de alunos desinteressados na aprendizagem, o que resulta no sentimento de insuficiência da atuação docente por si só. Neste sentido, há narrativas que expõem a tentativa por parte dos professores de instigar a reflexão, o que não se distingue entre as diferentes redes de ensino. De acordo com Misoczky e Goulart (2011), é justamente esta a função da universidade: a responsabilidade de refletir, criticar e anteciparse na construção de alternativas.

Nesse sentido, acho que é a gente poder ser uma peça na transformação, é poder fazer com que essa massa crítica assim, possa... ah, eu posso pensar! Tu vês o brilho no olho de alguns estudantes, né? Parece que eles saíram de um estado e foram para outro. É meio que o mito da caverna de Platão. Saiu de um estado e foi para outro. Eles conseguiram aquilo, mas tu foste o instrumento (Amora).

Existe também uma preocupação com a transmissão de experiência, com a aprendizagem do conteúdo por parte do aluno e do estabelecimento de redes de relações, de forma a auxiliá-lo na inserção profissional. Camila relata a importância de transmitir o que aprendeu no decorrer da carreira com o objetivo de "tentar contribuir para o crescimento profissional de uma pessoa". 
Fernando declara: “falo para o pessoal, o que tu estás buscando aqui na sala de aula além do conhecimento. Buscando teu networking, teu cartão de visitas está aqui", o que indica o sentimento de reconhecimento do trabalho docente como um agente de transformação do social pela educação.

\section{Imagem da profissão}

Nessa categoria ficou evidente a percepção comum de divergência entre o sentido do trabalho para o docente e a imagem que a sociedade faz da docência. Isso irá influenciar o sentimento de autorrealização inerente à racionalidade subjetiva (Andrade, Tolfo e Dellagnelo, 2012) no processo de constituição da identidade do trabalhador, uma vez que interfere na forma como ele se vê no campo social que atua (Dejours, 2007).

A frase "você só dá aula ou trabalha também?", mencionada pela maioria dos entrevistados quando falam sobre a profissão, reflete a simplificação da atividade docente por parte da sociedade que percebe como trabalho efetivo do docente apenas o período de aula, e ignora as demais atividades vinculadas ao ensino: “A gente está atendendo aluno, a gente está respondendo e-mail, a gente está corrigindo trabalho" (Brenda). Em complemento, Amora diz que "tem muito disso na nossa sociedade, infelizmente, de não enxergar o papel da construção, que o docente é um pesquisador, ele é um agente de transformação, ele não é só aquele profissional que vai aquele momento na sala, larga um conteúdo, existe toda uma reflexão por trás".

Essa simplificação - que aparece na fala dos próprios entrevistados quando falam que deixaram outras atividades para serem 'só docentes' - não considera as demais dimensões de atuação na profissão, tais como a extensão, a pesquisa e a gestão nas quais são cobrados a participar, bem como de toda a preparação e formação que o ensino exige. No mais, os dados sugerem que o docente de nível superior ainda encontra desafios no sentido de inserir-se com legitimidade profissional, já que esta também é considerada para alguns uma segunda jornada, que aparece como complemento financeiro e pessoal. Essa característica atribuída ao docente do ensino superior difere, portanto, do professor de ensino médio e fundamental que sugere ter buscado a realização de uma atividade de ensino como primeira opção. Ao contrário, muitos dos professores do ensino superior, especialmente presentes nas instituições particulares, acabam se engajando na docência por acaso, sem abrir mão de outros vínculos laborais. 


\section{Sentimento de vinculação com o trabalho}

A atuação do docente vai além do âmbito do ensino, em um atendimento do âmbito do sentido substantivo do trabalho mais elevado do que no sentido instrumental indicado por Andrade, Tolfo e Dellagnelo (2012). Entretanto, nas instituições públicas essa atuação é percebida de forma diferente de como o é nas instituições privadas.

Nas instituições públicas, é visível o envolvimento dos docentes com a gestão e a vinculação com a instituição de ensino - se colocam nas falas como parte da instituição: "nós, na nossa instituição, temos essa visão..." “a gente já evoluiu...". Dessa forma, foi percebida uma ativa participação docente na instituição pública que é fomentada pelas instâncias da pesquisa, extensão e gestão, o que produz vínculos institucionais na medida em que resultam na progressão de carreira dado que difere da rede privada, na qual o não engajamento pode levar à demissão.

Na rede pública, ainda, foi evidenciado sentimento de vinculação à atividade docente, como transparece nas palavras de Brenda:

Acho que dentro de todas as dificuldades que eu tive até hoje, uma das coisas que não é difícil para mim é trabalhar e ser professora (...) acho que isso realmente foi onde eu me encontrei.

Nenhum dos docentes da área pública cogita mudar de profissão. Já nas instituições privadas, o compromisso é com o aluno:

Às vezes vou (eventos da instituição) (...) mas eu faço questão só de sempre estar presente em sala de aula. Isso eu acho que é meu grande compromisso, com o aluno" (Douglas).

Neste caso, na rede privada, a docência é vista como a segunda profissão:

Não que eu não me sinta realizada como professora, apenas eu acho que ainda falta algo além de ser professora para preencher a minha realização plena" (Camila).

Outro fator que impede que a docência seja a principal atividade na rede particular é a remuneração insuficiente, em especial ao se considerar a escolaridade exigida, "com salário de professor a gente não vive" (Lucas). Para Camila,

(o fator financeiro) fica em segundo plano porque eu canso de fazer coisas além e sem remuneração. (...) As cobranças são maiores do que o retorno financeiro.

A partir de dados obtidos nas entrevistas, identificou-se que os professores da rede particular recebem, em média, menos que a metade do que recebem os professores da rede pública. Dessa forma, o fator financeiro não deixa de 
ser relevante, mas não é o principal fator considerado para a atuação. Gostar de lecionar é fator bastante salientado, o que ratifica a preponderância do sentido substantivo do trabalho sobre o sentido instrumental (Andrade, Tolfo e Dellagnelo, 2012).

Na rede pública a remuneração é vista como adequada, levando em consideração a situação econômica vigente e as exigências do cargo, o que traz tranquilidade ao desempenho das atividades. Como não é uma preocupação, a busca pela recompensa material cede lugar a outras buscas: "tu vales assim pelo que tu podes transformar, pelo que tu podes contribuir e isso não tem preço, não consegue fazer num cálculo" (Amora).

Serva (1997) aponta o sentimento de autorrealização, aliado ao de desenvolvimento e aprendizagem. Nesse sentido, foi apontado na rede pública que a instituição apoia a formação e capacitação do docente, mas não fornece esse desenvolvimento. Segundo os participantes, "nós temos o período, a cada cinco anos nós temos a saída para capacitação, o que é ótimo, tem um horário especial de estudante" (Maurício), e "para participar de qualquer evento, qualquer capacitação, isso eles te ajudam, eles te liberam, tem a questão de horas. Agora, que eles ofereçam, já não são tantas" (Brenda). Ou seja, o docente tem meios para buscar a formação e a atualização, mas a responsabilidade pela busca desses meios é exclusivamente dele. Pode acontecer de ele não buscar a formação e a atualização, já que não é obrigado a tal, mas se o fizer é recompensado e seu acesso à formação é facilitado com benefícios.

Já na rede particular, foi percebido um sentimento de desamparo quanto à continuidade de um aperfeiçoamento técnico. Ao tempo que se espera deles a formação contínua, não lhes dão suporte para tal. Marina conta sobre a necessidade de realizar um curso sem receber nenhum incentivo, inclusive pagando a mensalidade integralmente, e complementa:

\footnotetext{
A instituição quer que a gente produza artigos científicos, faça grupo de estudos, que dê mais atenção para o aluno, mas a gente não ganha nada por isso. O professor vai fazer esse trabalho de muito bom gosto, mas ao mesmo tempo é um tempo que o professor está tirando da vida dele para poder suprir essa necessidade que a instituição está demandando.
}

Um fator comum entre os docentes, visto como o mais relevante para a autorrealização e vinculação com a atividade, é o reconhecimento percebido por parte dos alunos, notado por agradecimentos pessoais, e-mails, homenagens em redes sociais e na escolha como paraninfo ou homenageado da turma, ou mesmo respeito e prestígio percebido quando da produção acadêmica valorizada. O reconhecimento não necessariamente advém do resultado direto da disciplina lecionada, mas das consequências da interação entre aluno e professor, tais como a certeza do curso a ser feito, como 
afirma Fernando, ou em ser a semente de transformação do aluno, tal como alega Amora.

\section{Sentimento de pertença a uma classe trabalhadora}

O desejo de ser professor foi destacado, ainda que a visão acerca do que é ser professor ou de sua função social, como mencionado, não seja a mesma e esteja constantemente em construção:

Eu entro antes, faço todo o cenário, dou as boas-vindas, converso e quando são sete e meia, vamos começar a aula. Mas tem que ter aquele envolvimento de estar com alguém, interferir na vida de alguém e que essa pessoa interfira na tua vida. É esse compartilhar, é esse estar junto ao ser humano que está ali contigo. Então, eu amo ser professora (Daniela).

Verificar as deficiências de cada aluno, não só no estudo, mas também em relação a sua vida. Porque muitas vezes a gente é meio psicólogo dos alunos e ajuda eles em outras situações (Marina).

Assim, mesmo que todos apresentem vínculo com a atividade da docência, o considerar-se professor leva a sentido e a funções diversas, bem como exige diferentes envolvimentos. Contudo, essa identificação é maior com a atividade ou com o que se acredita ser essa atividade do que com a classe docente, o que é acentuado pelo sentimento de diferenciação entre os níveis de ensino. Isso se comprova pela baixa adesão aos organismos de classe. Dentre os entrevistados, apenas Daniela participa de uma organização de mobilização docente, o que enfatiza o distanciamento da classe docente dos demais trabalhadores. Maurício, Douglas e Fernando participam dos conselhos regionais de classe das respectivas áreas. Os docentes afirmam que esse fator mereceria atenção, mas não acreditam nos organismos vigentes, repudiando sua atuação. Também, por serem muitas as entidades, alegam haver enfraquecimento e desconexão das informações recebidas.

A despeito dos motivos, a não constituição enquanto classe institui obstáculo à construção da consciência coletiva do trabalho, bem como à compreensão do contexto histórico e social da classe (Antunes, 2003, 2014; Souza, 2010; Ferraz, 2015). Enquanto isso, as grandes corporações que têm direcionado os seus investimentos ao ensino superior enquanto mercadoria, reproduzem o processo de mundialização capitalista da 'nova globalização' (Vasapollo, 2005), o que inclui a educação como produto no rol da especulação da financeirização econômica e do domínio da bolsa de valores. Este processo global irreversível cria e recria constantes formas variadas de desigualdade (Cattani, 1996), o que 
deixa pessoas sem trabalho e, quando muito, promove a precarização pelos e nos modos de flexibilizar os vínculos laborais.

\section{Flexibilização do trabalho}

Os docentes entendem o seu trabalho como inerentemente flexibilizado e por isso não há juízo de valor: a flexibilização não é positiva ou negativa, mas uma necessidade que leva a consequências.

Os professores do ensino público, ao verem a flexibilização como fonte de benefícios e adequada à natureza da profissão, negam o ponto como instrumento de gestão válido para mensuração de trabalho e acreditam que fere a liberdade de atuação. O ponto eletrônico foi instituído em uma instituição da rede pública, mas apresenta constante controvérsia a sua aplicação.

A colocação do ponto eletrônico foi muito ruim. Porque a gente não tem horário. Então vai ser muito melhor eu ir ali fora olhar a paisagem ou ir pra casa e fazer uma aula diferente. Mas eu tenho que vir aqui, nesse quadradinho. Eu me sinto aprisionada por isso. (...) E aí se eu não tiver conseguindo construir uma aula legal no horário de trabalho, não vou fazer naquele momento e vou fazer num outro. Eu tenho mais trabalho por conta disso. Porque algo que eu poderia estar fazendo em casa eu tenho de vir aqui porque tem horário pra registrar e tal (Amora).

Ainda, a flexibilidade traz liberdade e tem como consequência uma maior necessidade de disciplina, o que responsabiliza o docente pela sua atuação. Os docentes afirmam executar atividades profissionais em seus domicílios, inclusive nos finais de semana. Brenda prefere corrigir trabalhos e orientar alunos nos finais de semana, devido ao acúmulo de atividades (cursava doutorado à época da entrevista). Os estudos para os cursos e a produção acadêmica também ocorrem fora do horário de trabalho. Maurício destaca que há trocas de horários, no ambiente de trabalho são efetuadas atividades não inerentes ao contratado (como organização de eventos de extensão, comitês de ética, editorial de revistas, reuniões de colegiado etc.), o que faz com que as atividades profissionais sejam efetuadas em casa. Também, os ocupantes de cargo dizem que este é acumulado com outras atividades. Assim, no horário 'do ponto' são priorizadas as atividades presenciais como aulas, atendimento a aluno, comissões, reuniões. Com isso, a organização do trabalho dita a organização das demais instâncias da vida do trabalhador, além da forma como o trabalhador se vê e vê sua vida. Ou seja, a organização do trabalho contribui para que este se constitua como importante forma de subjetivação, como aponta Dejours (2007) e Birman (2006). 
Ademais, Brenda, Lucas e José ratificam a necessidade de planejar e organizar o cotidiano de forma diversa, mas gostam do fato de isto não levar a uma rotina, justamente por dar maior liberdade na distribuição dos horários das suas vidas. Entretanto, Amora e Maurício culpam a si mesmos por terem dificuldade de lidar com esta autonomia na gestão do tempo. Assim, se veem indisciplinados e sentem que a invasão do trabalho nas instâncias da vida pessoal prejudica as suas relações íntimas. A culpa que resulta da flexibilização frente à sobrecarga de trabalho é ressaltada por José:

Tenho colegas que eu me relaciono em alguns comitês que eu participo em outras instituições mais recentes que o nosso e eles têm o mesmo sentimento, que se não der certo é culpa nossa. Então a gente tem que fazer tudo.

José acrescenta que a dificuldade para a compreender a natureza do trabalho docente, afeita à abstração e inspiração, não é entendida pelas instituições responsáveis pelo controle do trabalho. Conforme relato,

talvez esse seja um grande ponto hoje que não se chega a um consenso entre a classe e as instituições, porque todo mundo concorda que flexibilizar é bom, mas, frente ao órgão de controle, nada melhor do que apresentar o ponto (José).

Para os docentes das instituições privadas o trabalho flexibilizado é algo naturalizado, e vai ao encontro das concepções contemporâneas de trabalho no capitalismo (Vasapollo, 2005; Antunes, 2005; Mészáros, 2009). Douglas acredita que docentes precisam ter pré-disposição para trabalhar em casa, e diz lidar bem com isso, mas vê a obrigação de trabalhar à noite (maioria dos casos dos cursos superiores) como um desmotivador. Daniela diz que tira o pijama, toma banho e se arruma mesmo que trabalhe em casa, para se conscientizar da atividade. Camila afirma que o trabalho desempenhado em casa não 'aparece', pois não é entendido como trabalho aos olhos da sociedade. Enquanto Fernando ressalta que há diferenças na rede particular entre a atuação do docente 40 horas, que tem uma carreira a zelar, e o horista, especialmente o que tem carga horária baixa. Para este, a docência é considerada 'um bico', e não há como cobrar maior comprometimento sequer com as dimensões pedagógico-didáticas de sala de aula.

Para Vasapollo (2005, p. 28), a flexibilização é uma "imposição à força de trabalho para que sejam aceitos salários reais mais baixos e em piores condições". Assim, a abertura do ensino enquanto mercado de especulação financeira, embora amplie o acesso da população à educação, se apropria de uma função que o Estado (propositalmente) não desempenha. Por sua vez, essas corporações, ao comercializarem um modelo de ensino questionável, também difundem o trabalho irregular, precário e sem garantias aos docentes, cujo reflexo na vida pessoal é imediato. 


\section{Sentimento da relação entre vida pessoal e vida profissional}

Há outros fatores que indicam que o trabalho docente invade as instâncias da vida pessoal, em um imbricar que leva à constituição da identidade do docente e novamente ratifica as obras de Dejours (2007) e Birman (2006). Amora relembra que diferente de como agia na indústria onde trabalhava, não consegue deixar de ser docente nos finais de semana, o que fecha a porta do trabalho na sexta para retomá-lo na segunda-feira: “Eu não diria que eu sou docente só na sala de aula".

José adiciona que vida pessoal e profissional se confundem na atuação pública, pelo fato de o docente em dedicação exclusiva poder ser requisitado a atuar em qualquer turno de trabalho. Mas a interlocução entre vida pessoal e profissional é confirmada por Camila e Marina na rede particular também. Outras questões indicam as modificações que o trabalho trouxe, como as relações sociais. Os entrevistados afirmaram não terem mudado suas relações, mas agregado novas através do trabalho, e então novos círculos são integrados.

A visão de si mesmo também se modifica com base no trabalho (SouzaLobo, 2011; Harvey, 2001). Amora diz que devido a educação permear muitos espaços, há enriquecimento, ganho em relacionamento humano, em aprender a lidar com os limites e medos. Fernando diz que a docência ampliou seu amadurecimento, qualidade pessoal mais ressaltada como consequência da interação necessária à docência, além da paciência, qualidade relevada por José e Mariana: “O Fernando antes da docência era muito limitado em enxergar a vida".

Os conhecimentos da prática de atuação profissional são agregados à atuação em sala de aula, o que evidencia a dimensão que o trabalho toma na vida do docente. Assim, modos de ser são transformados em detrimento do desenvolvimento pessoal produzido na interação com o trabalho, o que traz novos sentidos ao exercício docente.

\section{O sentido final}

Nas análises, foram apresentados elementos que resultam na construção da subjetividade dos docentes através do sentido que atribuem ao trabalho. Quanto às racionalidades, os elementos indicam a preponderância do sentido substantivo do trabalho sobre o sentido instrumental. Sobre este último, que inclui a flexibilização, por exemplo, é possível compreender que há uma alteração na percepção da atuação individual do trabalhador e incide 
sobre o sentido substantivo, e é capaz de alterar as próprias noções acerca do significado do trabalho em si.

Como resultado dos elementos percebidos, os docentes de nível superior entrevistados veem o seu trabalho como relevante socialmente na medida em que conseguem transformar ou serem instrumento de transformação dos alunos que carregam este desejo por mudanças. Sentem-se, assim, corresponsáveis pelo ensino, no entanto, por mais que se dediquem, sua atuação não será suficiente para que a etapa desejada se complete. O sentido do seu trabalho é, assim, a realização através do transformar, pensar e fazer refletir, desenvolver-se e desenvolver, viver pessoal e profissionalmente. Assim, como em Dejours (2007), o trabalho se constitui mediador da realização pessoal no campo social e produtor de subjetividades.

Para além, na interação entre variáveis pessoais e ambientais relacionadas ao trabalho, em que os sentidos a ele atribuídos se relacionam às racionalidades instrumental e substantiva (Andrade, Tolfo e Dellagnelo, 2012), ao mesmo tempo que há um sentimento de identificação com a área de formação, há identificação maior com a docência e dela se espera autorrealização. Entretanto, isso estende o número de habilidades necessárias para atuação: as específicas, que dizem respeito aos conhecimentos técnicos de área; as de docência, que contemplam a didática voltada ao ensino superior e, ainda, as habilidades necessárias para produção acadêmica, de pesquisa e escrita, requeridas ao longo da formação. Assim, nessa trajetória de atuação docente, a vida e a visão de si são transformadas em constante (embora sempre incompleto) processo de amadurecimento pessoal, profissional e social.

Os docentes acreditam que a visão da sociedade a respeito de suas atividades é simplificada, pois sabem que a sua atuação perpassa muitas outras atividades além das horas em que estão em sala de aula. Mesmo que se sintam docentes e que a relação com a profissão tenha sido apresentada como significativa, a preocupação como consciência de classe não foi ainda construída. Assim, há uma individualização de atuação. Isso resulta em um docente responsabilizado integralmente pela sua formação e também pela atuação profissional e pela disciplina na organização para que isto ocorra.

É nesse âmbito que existe a possibilidade de as relações de trabalho incidirem no sentido do trabalho docente. As falhas que acontecem no processo de aprendizagem e o não dar conta de atuar no regime de flexibilização levam à culpabilização do docente individualmente. A flexibilização que permite a organização do dia a dia com maior liberdade também leva ao imbricar da vida pessoal e profissional do docente. Ele precisa, assim, aprender a dinâmica imposta pela flexibilização das jornadas: ou seja, cria-se a demanda de organização da vida com base na falta de garantias trabalhistas, na remuneração variável, na ausência de uma agenda de trabalho constante e linear etc. Não basta ciclicamente aprender mais, ser mais, fazer mais, é preciso organizar-se 
melhor, planejar-se a cada novo semestre de trabalho. O sentido nunca está completo, mas é um constante fazer-se e inventar-se na interlocução de infinitas combinações de sociabilidades com individualidades, em um contingente efêmero e mutante.

\section{Colaboradores}

Anelise D'Arisbo fez a discussão inicial com a segunda autora que resultou na ideia/problemática do artigo; construção inicial e primeira revisão do referencial teórico; realização de parte da pesquisa de campo e respectiva transcrição; construção inicial das categorias de dados; primeira construção da discussão dos dados e das considerações finais. Daiane Boff auxiliou na construção do referencial teórico; realização de parte da pesquisa de campo e respectiva transcrição; auxílio na organização e análise dos dados e na construção das categorias; reflexão sobre os dados e problemática. Andrea Poleto Oltramari colaborou na análise dos dados e construção das categorias; na construção do referencial teórico; e na reflexão sobre os dados e problemática. Julice Salvagni participou da análise dos dados e na construção do referencial teórico; na problemática e revisão final.

Resumen Este artículo objetivó comprender el sentido del trabajo para el docente de enseñanza superior en instituciones públicas y privadas en sus diversos regímenes de flexibilización del trabajo, a partir de la identificación de elementos de la racionalidad instrumental y subjetiva. Así, la recolección de datos contó con fuentes múltiples, tales como el análisis documental de las instituciones y de los contratos de trabajo de los docentes, la observación directa y entrevistas realizadas presencialmente. Como resultado se percibió que: hay preponderancia del sentido sustantivo del trabajo sobre el sentido instrumental; la flexibilización altera la percepción de la actuación individual e tiene impacto sobre su sentido sustantivo; y la vida se organiza a partir de la organización del trabajo flexibilizado.

Palabras clave sentido del trabajo; enseñanza; flexibilización.

\section{Nota}

${ }^{1}$ Instituto Federal de Educação, Ciência e Tecnologia do Rio Grande do Sul, Farroupilha, Rio Grande do Sul, Brasil.

$<$ anelise.darisbo@farroupilha.ifrs.edu.br>

Correspondência: Av. São Vicente, 785, CEP 95180-000, Farroupilha, Rio Grande do Sul, Brasil. 


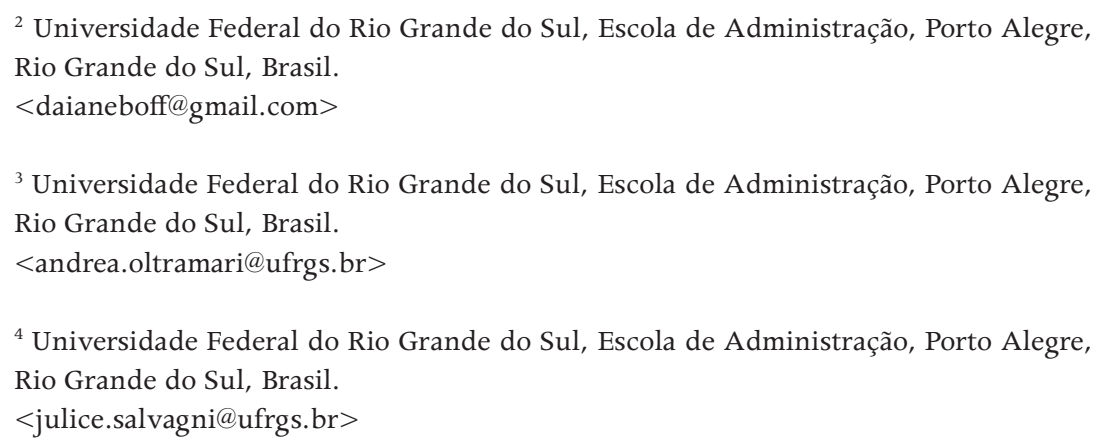

\section{Referências}

ALCADIPANI, Rafael. Academia e a fábrica de sardinhas. Organizações e Sociedade, Salvador, v. 18, n. 57, p. 345-348, 2011.

ANDRADE, Sílvia C.; TOLFO, Suzana R.; DELLAGNELO, Eloise L. Sentidos do trabalho e racionalidades instrumental e substantiva: interfaces entre a administração e a psicologia. Revista de Administração Contemporânea, Curitiba, v. 16, n. 2, p. 200-216, abr. 2012.

ANTUNES, Ricardo. O caracol e sua concha: ensaios sobre uma nova morfologia do trabalho. São Paulo: Boitempo, 2005.

ANTUNES, Ricardo. A classe-que-vive-dotrabalho: a forma de ser da classe trabalhadora hoje. In: ANTUNES, Ricardo. Os sentidos do trabalho: ensaio sobre a afirmação e a negação do trabalho. 6. reimp. São Paulo: Boitempo, 2003.

ANTUNES, Ricardo. Riqueza e miséria do trabalho no Brasil III. Boitempo: São Paulo, 2014.

ARAÚJO, Romilda R.; SACHUK, Maria I. Os sentidos do trabalho e suas implicações na formação dos indivíduos inseridos nas organizações contemporâneas. Revista de Gestão da Universidade de São Paulo, São Paulo, v. 14, n. 1, p. 53-66, 2007.

BALL, Stephen J. Performatividade, privatização e o pós-estado do bem-estar. Educação $e$ Sociedade. Campinas, v. 25, n. 89, p. 1.1051.126, set.-dez. 2004.
BARDIN, Laurence. Análise de conteúdo. Tradução de Luís Antero Reto e Augusto Pinheiro. Lisboa: Edições 70, 2000.

BARRETTO, Elba S. S. Trabalho docente e modelos de formação: velhos e novos embates e representações. Cadernos de Pesquisa, São Luiz, v. 40, n. 140, p. 427-443, 2010.

BIRMAN, Joel. Sobre o mal-estar na modernidade e na brasilidade. In: BIRMAN, Joel. Arquivos do mal-estar e da resistência. Rio de Janeiro: Civilização Brasileira, 2006.

CACETE, Núria H. Breve história do ensino superior brasileiro e da formação de professores para a escola secundária. Educação e Pesquisa, São Paulo, v. 40, n. 4, p. 1.061-1.076, 2014.

CATTANI, Antonio. Trabalho e autonomia. Petrópolis: Vozes, 1996.

CHAHAD, José P. As modalidades especiais de contrato de trabalho na CLT e a flexibilidade do mercado de trabalho brasileiro. In: CHAHAD, José P.; CACCIAMALI, Maria C. Mercado de trabalho no Brasil: novas práticas trabalhistas, negociações coletivas e direitos fundamentais no trabalho. São Paulo: LTr, 2003.

COLLI, Juliana. A trama da terceirização. Campinas: Editora da Unicamp, 2000.

DEJOURS, Cristhofe. Prefácio. In: MENDES, Alvaro M. Psicodinâmica do trabalho: teoria, método e pesquisas. São Paulo: Casa do Psicólogo, 2007. p. 19-22. 
FERRAZ, Denise L. Projetos de geração de trabalho e renda e a consciência de classe dos desempregados. Organizações e Sociedade, Salvador, v. 22, n. 72, p. 123-141, jan.-mar. 2015.

HARVEY, David. Condição pós-moderna. 10. ed. São Paulo: Loyola, 2001.

INEP. Instituto Nacional de Estudos e Pesquisas Educacionais Anísio Teixeira. Notas sobre o censo da educação superior 2014. Disponível em: $<$ http://inep.gov.br>. Acesso em: 17 out. 2016.

LINHARES, Antonio P.; SIQUEIRA, Marcus S. Vivências depressivas e relações de trabalho: uma análise sob a ótica da psicodinâmica do trabalho e da sociologia clínica. Cadernos EBAPE.BR, v. 12, n. 3, p.719-740, 2014.

LANCMAN, Selma; SZNELWAR, Laerte. Christophe Dejours: da psicopatologia à psicodinâmica do trabalho. Rio de Janeiro: Editora Fiocruz; Brasília: Paralelo 15, 2004.

MÉSZÁROS, István. A crise estrutural do capital. São Paulo: Boitempo, 2009.

MINAYO, Maria C. S. (org.). Pesquisa social: teoria, método e criatividade. 28. ed. Petrópolis: Vozes, 2011.

MISOCZKY, Maria C.; GOULART, Salete. Viver as contradições e tornar-se sujeito na produção social de nosso espaço de práticas. Organizações e Sociedade, Salvador, v. 18, n. 58, p. 535-540, 2011.

MORIN, Estelle. Os sentidos do trabalho. Revista de Administração de Empresas, São Paulo, v. 41, n. 3, p. 8-19, jul.-set. 2001.

NASCIMENTO, Luis F. Modelo capes de avaliação: Quais as consequências para o triênio 20102012? Administração: Ensino e Pesquisa. Rio de Janeiro, v. 11, n. 4, p. 579-600, 2010.

PAULA, Maria F. A formação universitária no Brasil: concepções e influências. Avaliação, Campinas, v. 14, n. 1, p. 71-84, 2009.

PICCININI, Valmíria C.; ROCHA-DE-OLIVEIRA, Sidinei; RUBENICH, Nilson V. Formal, flexível ou informal? In: PICCININI, Valmíria C. et al. (orgs.). O mosaico do trabalho na sociedade contemporânea: persistências e inovações. Porto Alegre: Editora UFRGS, 2006.

ROCHA-DE-OLIVEIRA, Sidinei; PICCININI, Valmíria C. Contribuições das abordagens francesas para o estudo da inserção profissional. Revista Brasileira de Orientação Profissional, São Paulo, v. 13, n. 1, p. 63-73, 2012.

SERVA, Maurício. Racionalidade substantiva demonstrada na prática administrativa. Revista de Administração de Empresas, São Paulo, v. 37, n. 2, p. 18-30, 1997.

SILVA, Mônica P.; SIMÕES, Janaína M. O estudo do sentido do trabalho: contribuições e desafios para as organizações contemporâneas. Capital Cientifico, Guarapuava, v. 13, n. 3, p. 136-151, 2015.

SOUZA, Jessé. Os batalhadores brasileiros: nova classe média ou nova classe trabalhadora? Belo Horizonte: Editora UFMG, 2010.

SOUZA-LOBO, Elisabeth. A classe operária tem dois sexos: trabalho, dominação e resistência. São Paulo: Fundação Perseu Abramo, 2011.

SPINK, Peter; ALVES, Mario A. O campo turbulento da produção acadêmica e a importância da rebeldia competente. Organizações e Sociedade, Salvador, v. 18, n. 57, p. 337-343, abr.-jun. 2011. Disponível em: <http://www.revistaoes. ufba.br>. Acesso em: 15 jul. 2016.

TOLFO, Suzana R.; PICCININI, Valmíria. Sentidos e significados do trabalho: explorando conceitos, variáveis e estudos empíricos brasileiros. Psicologia e Sociedade, Belo Horizonte, v. 19, n. esp., p. 38-46, 2007.

VASAPOLLO, Luciano. O trabalho atípico e a precariedade. São Paulo: Expressão Popular, 2005.

VERGARA, Sylvia C. Projetos e relatórios de pesquisa em administração. 7. ed. São Paulo: Atlas, 2006.

Recebido em 02/03/2017.

Aprovado em 20/05/2017. 